\title{
Population Structure of Pythium irregulare, P. ultimum, and P. sylvaticum in Forest Nursery Soils of Oregon and Washington
}

\author{
Jerry E. Weiland, Patricia Garrido, Zhian N. Kamvar, Andrés S. Espíndola, Stephen M. Marek, \\ Niklaus J. Grünwald, and Carla D. Garzón
}

First and sixth authors: U.S. Department of Agriculture-Agriculture Research Service, Horticultural Crops Research Laboratory, and Department of Botany and Plant Pathology, Oregon State University, Corvallis, OR 97331; second, fourth, fifth, and seventh authors: Department of Entomology and Plant Pathology, Oklahoma State University, Stillwater, OK 74074; and third author: Department of Botany and Plant Pathology, Oregon State University, Corvallis, OR 97331.

Accepted for publication 18 December 2014.

\begin{abstract}
Weiland, J. E., Garrido, P., Kamvar, Z. N., Espíndola, A. S., Marek, S. M., Grünwald, N. J., and Garzón, C. D. 2015. Population structure of Pythium irregulare, P. ultimum, and P. sylvaticum in forest nursery soils of Oregon and Washington. Phytopathology 105:684-694.

Pythium species are important soilborne pathogens occurring in the forest nursery industry of the Pacific Northwest. However, little is known about their genetic diversity or population structure and it is suspected that isolates are moved among forest nurseries on seedling stock and shared field equipment. In order to address these concerns, a total of 115 isolates of three Pythium species (P. irregulare, P. sylvaticum, and P. ultimum)

were examined at three forest nurseries using simple sequence repeat (SSR) and amplified fragment length polymorphism (AFLP) markers. Analyses revealed distinct patterns of intraspecific variation for the three species. $P$. sylvaticum exhibited the most diversity, followed by $P$. irregulare, while substantial clonality was found in $P$. ultimum. For both $P$. irregulare and $P$. sylvaticum, but not $P$. ultimum, there was evidence for significant variation among nurseries. However, all three species also exhibited at least two distinct lineages not associated with the nursery of origin. Finally, evidence was found that certain lineages and clonal genotypes, including fungicide-resistant isolates, are shared among nurseries, indicating that pathogen movement has occurred.
\end{abstract}

Pythium species are common, important soilborne pathogens that cause damping-off and root rot in forest nurseries of the Pacific Northwest of the United States and Canada $(12,57)$. Approximately 20 species have been found in forest nursery soils of the region $(28,60)$. Of these, eight species, including $P$. dissotocum, $P$. irregulare, $P$. mamillatum, $P$. sylvaticum, and $P$. ultimum, are aggressive pathogens of tree seedlings and cause extensive Douglas-fir (Pseudotsuga menziesii) seedling mortality $(12,57,58,61)$.

Despite the widespread occurrence of Pythium species in forest nurseries and the significant amount of damage that they cause, nothing is known about the genetic diversity or population structure of key Pythium species present in these soils. For decades, disease management of soilborne pathogens and weeds has been largely accomplished via soil fumigation with a combination of methyl bromide and chloropicrin, or with other chemical fumigants $(40,62,63)$. Because of the broad spectrum nature of chemical fumigants, knowledge about soilborne pathogen identity, biology, and population structure was not necessary to achieve adequate disease control. However, with increasing state and federal regulatory pressure to restrict fumigant use, this information will be critical for developing and assessing the efficacy of new, more selective disease control measures.

Information about the structure of Pythium populations can be used to establish baseline estimates of Pythium genetic diversity among and within forest nurseries and will help determine the risks

Corresponding authors: J. E. Weiland; E-mail address: weilandj@ onid.orst.edu C. D. Garzón; E-mail address: carla.garzon@okstate.edu

*The $\boldsymbol{e}$-Xtra logo stands for "electronic extra" and indicates that six supplementary figures are published online.

http://dx.doi.org/10.1094/PHYTO-05-14-0147-R

This article is in the public domain and not copyrightable. It may be freely reprinted with customary crediting of the source. The American Phytopathological Society, 2015. associated with moving Pythium species from nursery to nursery on infested nursery stock or shared equipment $(27,63)$. Currently, many forest nurseries purchase seedling stock from other nurseries to help cover inventory shortfalls. In many cases, incoming seedlings are planted in production fields at the receiving nursery for additional shoot and root growth prior to sale. Roots of these incoming seedlings are often colonized by Pythium species and other soilborne pathogens from the source nursery, which may lead to contamination of field soils at the receiving nursery (62). Hansen et al. (27), for example, reported that tree seedlings infected with Phytophthora species were transplanted from one forest nursery into two other nurseries in the Pacific Northwest region. Subsequently, root rot was observed at all three locations. Although not yet documented, it is likely that Pythium species are also distributed in this manner, and this practice may inadvertently introduce new Pythium species or isolate genotypes into locations where they had not previously been found. In addition, field equipment (e.g., fumigation equipment, planters, etc.) is often used at multiple locations and may further compound the risk of accidentally moving pathogens from nursery to nursery.

Microsatellites and amplified fragment length polymorphisms (AFLPs) are molecular markers extensively used for DNA fingerprinting and assessment of gene diversity (10) among other applications. Although both techniques produce reproducible markers distributed throughout genomes, they differ in the nature of those markers. Microsatellites are characterized by using locus-specific polymerase chain reaction (PCR) primers, while AFLPs are generated using restriction site-specific primers that amplify DNA fragments located between restriction sites. Because of the manner in which each of these markers are identified, they differ in the kind of genomic information they provide. Microsatellites, such as simple sequence repeats (SSRs), are codominant markers that identify the different alleles at a locus, based on size differences between alleles, allowing the discrimination among homozygotes and heterozygotes in diploid organisms $(10,39)$. This intrinsic property of SSRs makes them extremely informative for 
population analyses, because they allow the assessment of allele diversity and frequency differences among populations. AFLPs on the other hand are scored based on the presence or absence of DNA fragments produced by restriction enzymes (59). The presence and absence of a restriction site reflects genetic variation among individual genotypes but does not provide any additional information about the loci such as where they are found or the reason why a restriction site may be absent. Therefore, AFLPs are considered dominant markers, cannot be used to unambiguously characterize alleles, or to identify homozygotes and heterozygotes (10). While 5 to 15 SSR loci can be used to characterize populations of 10 or more individuals, usually hundreds of AFLP markers and larger samples are needed to obtain similar population information. Nonetheless, because large numbers of AFLP markers are used, usually a better coverage of the genome is obtained. The information generated by SSR and AFLPs can be complementary and are often used in combination to obtain as much genetic information about populations as possible $(15,38)$. AFLPs have been used extensively for characterization of the genetic diversity of Pythium species, including $P$. irregulare sensu stricto (s.s., in the strict sense) (21-23), P. cryptoirregulare (23), P. myriotylum (52), P. spinosum (3), and $P$. aphanidermatum (2,4,34). Meanwhile, microsatellites have been infrequently used for characterization of Pythium species, and currently there are SSR markers available only for P. aphanidermatum, $P$. irregulare sensu lato (s.l., in the broad sense), P. cryptoirregulare $(34,35)$, and $P$. helicoides (68). Some of the SSR markers developed by Lee and Moorman (35) were transferable to several additional Pythium species, however their informativeness for population studies must be validated.

The objectives of this study were to assess and compare the level of genetic diversity and population structure of three common pathogenic Pythium species occurring in forest nurseries $(60,61)$ in order to determine whether isolates had been moved among three forest nurseries. Isolates of $P$. irregulare, $P$. sylvaticum, and $P$. ultimum were analyzed using microsatellite (SSR) and AFLP markers.

\section{MATERIALS AND METHODS}

Isolate selection. One hundred fifteen Pythium isolates were selected from the isolate collection of a previous survey (60) to be representative of the three most common and aggressive pathogenic Pythium species found in field soils at three forest nurseries in Washington (nursery A, Cagey loamy sand) and Oregon (nurseries B and C, Canderly sandy loam): P. irregulare (48 isolates), P. sylvaticum (37 isolates), and P. ultimum (30 isolates) $(60,61,62)$. A field plot (1.3 ha) was originally established at each nursery, each consisting of 12 equally sized subplots $(12 \times 46 \mathrm{~m})$. Composite soil samples were then collected from each subplot and Pythium species were isolated using one of three methods: soil dilution plating onto PARP agar, a semiselective medium for Pythiaceous species (33), or by baiting the soil with either rhododendron leaf disks or Douglas-fir needles (41). All Pythium isolates were identified on the basis of DNA sequence from the internal transcribed spacer (ITS) region and by morphology as described previously (60). Isolates of $P$. irregulare, $P$. sylvaticum, and $P$. ultimum were then selected to ensure that there was an approximately equal number of species isolates from each nursery. $P$. irregulare was isolated from all three nurseries $(\mathrm{A}=20$ isolates, $\mathrm{B}=18$ isolates, and $\mathrm{C}=10$ isolates), while $P$. sylvaticum $(\mathrm{B}=$ 17 isolates and $\mathrm{C}=20$ isolates $)$ and $P$. ultimum $(\mathrm{B}=12$ isolates and $\mathrm{C}=$ 18 isolates) were only isolated in sufficient numbers from nurseries $\mathrm{B}$ and C (60). These latter two species were rarely or never encountered in nursery A. Isolates of $P$. ultimum used in this study were not genetically similar to the zoospore-producing isolates identified as P. ultimum var. sporangiiferum $(14,18,37)$. Instead, $P$. ultimum isolates from this study shared 99 to $100 \%$ ITS sequence homology with the neotype of $P$. ultimum (var. ultimum), and are therefore considered P. ultimum s.s. $(14,37,60)$. Hyphal swellings and/or sporangia were present on a number of the P. ultimum isolates (e.g., ult A1-3, ult A2-5, ult C2-3, and ult C1-9), but their presence was not consistent in subsequent transfers. A preliminary analysis (data not shown) did not find that this characteristic was associated with any of the genetic markers utilized in this study. Therefore, the hyphal swelling phenotype was not investigated further. $P$. irregulare isolates used in this study are also considered $P$. irregulare s.s. (not $P$. cryptoirregulare or $P$. irregulare III and IV) based on 99 to $100 \%$ ITS sequence homology with $P$. irregulare s.s. isolates identified in previous studies $(22,23,37,45)$. All isolates were stored on colonized water agar plugs in sterile distilled water (both with and without sterilized wheat grass blades) at $20^{\circ} \mathrm{C}$.

SSR development, selection, and primer design. The SSR primer sets reported by Lee and Moorman (35) were used for $P$. irregulare $(n=21)$ and $P$. sylvaticum $(n=13)$. Because the three SSR markers previously reported for $P$. ultimum (35) were not informative, 22 new markers were developed (Table 1) from microsatellite sequences identified in the publicly available P. ultimum genome (36). The web software WebSat (44) was used to detect microsatellite motifs from genomic sequences. The search criteria were set to a minimum of six repeats of di- to hexa-nucleotides with perfect repeat motifs, annealing temperatures from 50 to $61^{\circ} \mathrm{C}$, differences between forward and reverse primers did not exceed $2^{\circ} \mathrm{C}$, predicted lengths of amplified products were set within 100 to $400 \mathrm{bp}$ in size, and guanine/cytosine content between 45 to $60 \%$. The Mfold web server (70) was used to predict secondary structures and to estimate the free-energy of the primers. All oligonucleotides were synthesized by Integrated DNA Technologies (Coralville, IA). Polymorphic markers were initially identified by screening all available SSR primer sets against a subset of four genetically distinct isolates of each species that had been previously characterized (data not shown) by intersimple sequence repeats analysis (ISSR) (69).

SSR analysis. Pythium isolates were grown in flasks containing $25 \mathrm{ml}$ of potato dextrose broth (Difco Laboratories, Detroit, MI) and incubated in the dark at $20^{\circ} \mathrm{C}$ for 5 days. The resulting mycelia were lyophilized and stored dry at $4^{\circ} \mathrm{C}$ until used. DNA extractions were performed from $30 \mu \mathrm{g}$ of dehydrated mycelium using DNeasy Plant Mini Kits (Qiagen, Valencia, CA), according to the manufacturer's instructions. DNA quality and concentration were measured using a NanoDrop ND-1000 spectrophotometer (NanoDrop Technologies, Wilmington, DE).

PCR amplifications of individual microsatellite loci were performed in $20-\mu \mathrm{l}$ reactions using $50 \mathrm{ng}$ of DNA, $2 \mu \mathrm{l}$ of $10 \times$ PCR buffer, $1.2 \mu \mathrm{l}$ of dNTP mixture, $0.15 \mu \mathrm{l}$ of Taq polymerase (buffer, dNTPs, and polymerase from TaKaRa Bio Inc., Japan), and $2 \mu \mathrm{l}$ of each $3 \mu \mathrm{M}$ primer. PCR temperature profiles were as follows: $94^{\circ} \mathrm{C}(2 \mathrm{~min})$, followed by 35 cycles of $94^{\circ} \mathrm{C} \mathrm{(30} \mathrm{s),} \mathrm{annealing} \mathrm{temperatures} \mathrm{ranged}$ from 55 to $60^{\circ} \mathrm{C}$ depending on the specific primer set (30 s), extension at $72^{\circ} \mathrm{C}(30 \mathrm{~s})$, and final extension at $72^{\circ} \mathrm{C}(10 \mathrm{~min})$. Annealing temperatures for $P$. irregulare and $P$. sylvaticum SSR primer sets were the same as in the original protocols (35), while the annealing temperatures of the new P. ultimum primers are reported in Table 1. PCR reactions were performed in a PTC-200 DNA engine thermal cycler (Bio-Rad, Hercules, CA). PCR products were separated by electrophoresis on $2.5 \%$ MetaPhor agarose gels (Lonza, Allendale, $\mathrm{NJ}$ ) at $95 \mathrm{~V} \mathrm{~cm}^{-1}$ for $9 \mathrm{~h}$. DNA fragments were visualized using a Gel Doc EZ system (Bio-Rad) and the imaging software LabWorks 3.0 (UPV, Upland, CA). Alleles at each locus were scored based on differences in size of PCR products, with a total of 128 alleles scored. Power Marker software version 3.25 (42) was used to determine allelic diversity, number of alleles per locus $(\mathrm{Na})$, effective number of alleles $(\mathrm{Ne})$, observed heterozygosity $(\mathrm{Ho})$, expected heterozygosity or gene diversity $(\mathrm{He})$ under Hardy-Weinberg equilibrium (HWE), polymorphism information content (PIC, a measure of the usefulness of a marker based on its level of polymorphism [6]), and fixation index $\left(F_{S T}\right.$, measures population differentiation based on the probability that alleles at any particular locus are identical by descent and where $F_{S T}<$ $0.05=$ low genetic differentiation; 0.05 to $0.15=$ moderate; 0.15 to $0.25=$ great; and, $>0.25=$ very great [66]) in each population across loci (65). The microsatellite genotypic matrix was converted to loci frequency data and computed at different hierarchical levels. The 
output was imported to NTSYSpc (Applied Biostatistics, Inc.) and used for UPGMA (unweighted pair-group method of averages) using genetic distances calculated using the simple matching coefficient. To examine hierarchical structure considering among- and withinpopulation diversity in each species, analysis of molecular variance (AMOVA) was performed using GenAlEx 6.5 (50), using the $F_{S T}$ analog $\Phi_{\mathrm{PT}}$ that can be used both with SSR and AFLP markers. The level of genetic flow among populations $\left(N m=\left[\left(1 / F_{S T}\right)-1\right] / 4\right)$ and Shannon's information index $(I)$ were estimated using POPGENE version 3.1 (67). Clusters identified by genetic relatedness and geographical distribution were used as references to define populations for $\mathrm{Nm}$ analysis. The standardized index of association $\left(\bar{r}_{d}\right)$ was used to evaluate the degree of clonal (asexual/inbreeding by strict selfing) reproduction (1). This index is conceptually similar to the index of association $\left(I_{A}\right)$ introduced by Brown (7) except that it corrects for the number of loci observed so that values can be compared across data sets with disparate numbers of loci sampled. Tests of significance were carried out by permuting alleles at each locus to simulate sexually recombining populations. $P$ values were obtained from 2,000 permutations. This was additionally performed on clone-censored populations where each multilocus genotype was represented only once per population as exact clones can bias the index (25). Minimum spanning networks were generated for each species across populations using Bruvo's genetic distance, which utilizes a stepwise mutation model for microsatellites $(8,11)$. Clone censoring, calculations of Bruvo's distance, the index of association, and permutation analyses were performed with poppr $\mathrm{R}$ package version 1.0.5 (32) in $\mathrm{R}$ (55).

STRUCTURE version 2.3.4 was used to assign individual genotypes to populations using a Bayesian approach (54). For this purpose, based on the index of association results, the three Pythium spp. populations were assumed clonal or with complete selfing, and each diploid individual was treated as haploid (20). Population information was used to test for migrants using the correlated allele frequencies between population models $(31,54)$. The length of the burn-in and MCMC (Monte Carlo Markov chain) were 10,000 and 100,000, respectively. STRUCTURE HARVESTER was used to determine the optimal value of $K(13)$.

AFLP analysis. AFLP (59) was performed on genomic DNA using the AFLP Microbial Fingerprinting protocol (Applied Biosystems (ABI), Foster City, CA) with slight modifications as described previously (25). Total genomic DNA was obtained from mycelia using the FastDNA SPIN kit (MP Biomedicals LLC, Solon, OH). DNA (20 ng) was digested, adaptors were ligated, and preselective amplifications with EcoRI core primer, MseI core primer, and AFLP amplification core mix were performed on a GeneAmp 9700 thermal cycler (ABI) as described (25). Preamplified samples $(10 \mu \mathrm{l})$ were diluted

TABLE 1. Primer set sequences developed to target specific sequences of repletion in Pythium ultimum

\begin{tabular}{|c|c|c|c|c|}
\hline Locus & Repeat motif & Size (bp) & Primer sequences $\left(5^{\prime}\right.$ to $\left.3^{\prime}\right)$ & $\mathrm{Ta}^{\mathrm{a}} / \mathrm{PCR}$ cycles \\
\hline PU001 & (AG) 10 & 378 & $\begin{array}{l}\text { TGATTACAAACCGTAGCCAGAC } \\
\text { TGGAACCAGACATCGCTCTAT }\end{array}$ & $60^{\circ} \mathrm{C} / 35$ \\
\hline PU002 & (AG)13 & 246 & $\begin{array}{l}\text { GATTGGCGCTACATACGATTT } \\
\text { CGTGCGTCTCATAACAGCATA }\end{array}$ & $60^{\circ} \mathrm{C} / 35$ \\
\hline PU003 & (CT) 11 & 316 & $\begin{array}{l}\text { AGGACCCTTTATAGCTGGGC } \\
\text { TTTGCTTGTTTGTAGAGGACGA }\end{array}$ & $60^{\circ} \mathrm{C} / 35$ \\
\hline PU004 & (AG) 10 & 361 & $\begin{array}{l}\text { GCGTGAGTATGTAGACGATTGC } \\
\text { TTCCAGCGTGAGGTATCTGTT }\end{array}$ & $60^{\circ} \mathrm{C} / 35$ \\
\hline PU005 & (CTGTAA)9 & 393 & $\begin{array}{l}\text { ACGGTCAATAACGTGCCAG } \\
\text { GACTCAAATTCAACTGGGTGTG }\end{array}$ & $60^{\circ} \mathrm{C} / 35$ \\
\hline PU006 & (GA)9 & 374 & $\begin{array}{l}\text { GTTCACTAACCCGTTTCCAGTC } \\
\text { CATAAGCGGTCGGTCTTTATTC }\end{array}$ & $60^{\circ} \mathrm{C} / 35$ \\
\hline PU007 & $(\mathrm{GAC}) 8$ & 395 & $\begin{array}{l}\text { ATCGGCTGAAAGTACCAGAGAG } \\
\text { GACATTCGTGGAGGAAATCTG }\end{array}$ & $60^{\circ} \mathrm{C} / 35$ \\
\hline PU008 & $(\mathrm{GT}) 14$ & 356 & $\begin{array}{l}\text { CGTAGTTCCAAGTGCTTCTGG } \\
\text { GACGAATAAAGTCCCACCATTC }\end{array}$ & $60^{\circ} \mathrm{C} / 35$ \\
\hline PU009 & (TA) 15 & 237 & $\begin{array}{l}\text { GCAGACACGGAGAAGACACATA } \\
\text { GATTGATCGGCCATTGTAAAGT }\end{array}$ & $60^{\circ} \mathrm{C} / 35$ \\
\hline PU010 & (TC) 9 & 373 & $\begin{array}{l}\text { TTATTTTGCTGTCCCGATCTGT } \\
\text { ATTGCTCTTGACCTTGTCCACT }\end{array}$ & $60^{\circ} \mathrm{C} / 35$ \\
\hline PU011 & $(\mathrm{AG}) 17$ & 252 & $\begin{array}{l}\text { CACGTAAAAGCCTCAAGACTCA } \\
\text { AAACTCTCATCACCACACAAGC }\end{array}$ & $60^{\circ} \mathrm{C} / 35$ \\
\hline PU012 & $(\mathrm{AC}) 11$ & 322 & $\begin{array}{l}\text { ACGTGTGGACTACTGCTGTCAT } \\
\text { TGACCTGAATACAAGCCCCTAT }\end{array}$ & $60^{\circ} \mathrm{C} / 35$ \\
\hline PU013 & (AT) 20 & 327 & $\begin{array}{l}\text { GTGGCCGAGTGTATAACGAAG } \\
\text { CAGTTTCAAGTGGTTTGTGTCC }\end{array}$ & $60^{\circ} \mathrm{C} / 35$ \\
\hline PU014 & (TG) 10 & 302 & $\begin{array}{l}\text { GGATTGCTGATGTTCACACCT } \\
\text { TTCTGGCTAAAATGGAGCTTCT }\end{array}$ & $60^{\circ} \mathrm{C} / 35$ \\
\hline P.ULT1 & $(\mathrm{GT}) 7$ & 123 & $\begin{array}{l}\text { AAAAGTGCTCTCGATTTCCATC } \\
\text { GATCCTCACACGTAAACGACAC }\end{array}$ & $60^{\circ} \mathrm{C} / 35$ \\
\hline P.ULT2 & (CA)6 & 216 & $\begin{array}{l}\text { GCTCTTTCTTCAGCCACTGTTT } \\
\text { GTCCACACAAGCTCTCTCTGC }\end{array}$ & $60^{\circ} \mathrm{C} / 35$ \\
\hline P.ULT3 & $(\mathrm{CT}) 12$ & 234 & $\begin{array}{l}\text { TGTTCTTCACGTTACCACAAGC } \\
\text { ACAGACACAGACACACACTCCC }\end{array}$ & $60^{\circ} \mathrm{C} / 35$ \\
\hline P.ULT4 & $(\mathrm{GCT}) 9$ & 241 & $\begin{array}{l}\text { GTCTCTCTCGAATGCACAAACA } \\
\text { GACAGATTACTGGAGCAGCCTT }\end{array}$ & $60^{\circ} \mathrm{C} / 35$ \\
\hline P.ULT5 & (G) 12 & 379 & $\begin{array}{l}\text { CCACACCGTCAAAACTTAGAAA } \\
\text { GTTACTGGTGGCATTCCTCTG }\end{array}$ & $59^{\circ} \mathrm{C} / 35$ \\
\hline P.ULT6 & $(\mathrm{CA}) 6$ & 396 & $\begin{array}{l}\text { TTCTACTGCTTTGTATGGTCGG } \\
\text { TTTCTATCAACAGTGCGTTCGT }\end{array}$ & $59^{\circ} \mathrm{C} / 36$ \\
\hline P.ULT7 & $(\mathrm{CA}) 8$ & 313 & $\begin{array}{l}\text { GTGGACTACTACTTCCCGAACG } \\
\text { CACGCAGCATATTGTACCTACC }\end{array}$ & $60^{\circ} \mathrm{C} / 35$ \\
\hline P.ULT8 & (TG)6 & 326 & $\begin{array}{l}\text { TCCATCAGCAGTCCACATTATC } \\
\text { ATACAGAATGGGTTGGTTGGTC }\end{array}$ & $60^{\circ} \mathrm{C} / 35$ \\
\hline
\end{tabular}

a $\mathrm{Ta}=$ annealing temperature. 
with $190 \mu \mathrm{l}$ of TE buffer and selective PCR was performed with $M s e \mathrm{I}-\mathrm{A} / E c o \mathrm{RI}-\mathrm{AC}$ and $M s e \mathrm{I}-\mathrm{T} / E c o$ RI-AT primer combinations. Products $(0.5 \mu \mathrm{l})$ were run with $25 \mu \mathrm{l}$ of loading buffer $(24 \mu \mathrm{l}$ of deionized formamide and $0.05 \mu \mathrm{l}$ of GeneScan-500 size standard, $\mathrm{ABI}$ ) on a capillary sequencer (ABI Prism 3100). Electropherograms were analyzed using GeneMapper software (version 3.7; $\mathrm{ABI}$ ) to extract a matrix of presence and absence of alleles in a range of 50 to $500 \mathrm{bp}$ after visual inspection. All AFLP analyses were replicated two or more times including independent restriction, PCR reactions, and electrophoresis until all polymorphic alleles could be unambiguously binned. All runs included a Phytophthora syringae reference strain as a positive control as used previously in AFLP analyses (26).

A total of 330 unambiguous and polymorphic markers were included in the population analyses of the three species. Parameters of genetic variability and population structure were estimated using GenAlEx 6.5 (50). Population structure was examined by AMOVA (16), UPGMA of Jaccard distances, and principal coordinate analysis (PCoA) (24) using GenAlEx and NTSYS. A dendrogram was created for combined AFLP data of the three species using UPGMA based on Felsenstein's restriction fragment distance using PHYLIP (17). This genetic distance takes restriction site mutations into account and is derived from Nei and Li's genetic distance (47). Statistical support for tree branches was obtained using 1,000 nonparametric bootstrap samples. Support is shown for values greater than or equal to $70 \%$.

Comparison of AFLP and SSR markers. The Mantel matrix correspondence test was performed using GenAlEx 6.5 (50) in order to compare the similarity matrices among SSR and AFLP markers. A tree topology distance test was performed in the $\mathrm{R}$ package APE version 3.1-4 (49) by comparing neighbor-joining trees constructed from dissimilarity matrices with the function dist.topo using the PH85 method, which does not take into account branch lengths (51). Furthermore, cluster analyses by UPGMA and PCoA, and population genetics statistics estimated using SSR and AFLP markers were compared.

\section{RESULTS}

Development of SSR markers for $P$. ultimum. Three SSR loci described by Lee and Moorman (35) for P. ultimum were monomorphic in our sample. One hundred sixty-six simple sequence repeats identified from the public $P$. ultimum genome were used for new microsatellite primer development. SSR primers were designed only for the loci carrying more than six di-, tri-, or tetranucleotide repeats. These loci did not overlap with the previously described markers (35). A total of 22 SSRs primer pairs were designed and screened for polymorphisms (Table 1). Amplicon size ranged from 123 to $396 \mathrm{bp}$. The number of alleles per locus varied from three to five. Only primer pairs that produced one (homozygous genotype) or two (heterozygous genotype) fragments per genotype were included in the study, under the assumption that all Pythium isolates were diploid. Five polymorphic loci were identified and used for characterization of all the $P$. ultimum isolates included in the study. Sequence analysis of the five polymorphic primers confirmed that the differences in size between alleles resulted from variation in the number of copies of the repetitive motif. Although the 22 primer pairs were tested on five $P$. irregulare and five $P$. sylvaticum isolates, no transferability was found.

Population analyses. AFLP analysis revealed distinctly different clades for each of the Pythium species with bootstrap support greater or equal to $99 \%$ (Fig. 1). Both primer combinations (AC-A and AT-T) showed homologous patterns of genetic diversity in these three species: $P$. sylvaticum was most diverse, followed by $P$. irregulare, while $P$. ultimum revealed the most clonality. The isolate placement within species did not reveal clades specific to a given nursery or sampling site (Supplementary Figs. 1 and 2).

In P. irregulare, $19 \%$ of the SSR loci and $87 \%$ of the AFLP markers were informative. SSR analysis revealed three to six alleles per SSR locus, the second largest mean expected and observed heterozygosities $(\mathrm{He}=0.65 ; \mathrm{Ho}=0.53)$, polymorphism information content (PIC $=0.59)$, number of private alleles, and Shannon's information index $(I=1.18)$ (Table 2, Fig. 2). AMOVA revealed significant low to moderate genetic differentiation $\left(\operatorname{SSR} \Phi_{\mathrm{PT}}=0.076\right.$; AFLP $\left.\Phi_{\mathrm{PT}}=0.105\right)$ among nursery populations. Gene flow analysis $(\mathrm{Nm}=6.38)$ suggested genetic exchange occurs among lineages (Table 2). UPGMA and PCoA of SSR (not shown) and AFLP data revealed two discrete isolate groups not associated with nursery of origin (Figs. 3 and 4; Supplementary Figs. 3A and 4). Sixteen of the isolates had unique AFLP genotypes, while 32 isolates belonged to 11 clonal lineages with up to six isolates each. One clonal lineage contained a single isolate from each of the three nurseries. STRUCTURE analysis of SSR data gave an optimum $K$ value of 2 (Fig. 5). According to STRUCTURE analysis, all isolates present in nurseries A and B had a high likelihood of having a local origin (Fig. 5). Most isolates present in nursery $\mathrm{C}$ were putative hybrids of the two lineages present in nurseries $\mathrm{A}$ and $\mathrm{B}$. The relatedness of isolates from nursery $\mathrm{C}$ to nurseries $\mathrm{A}$ and $\mathrm{B}$ isolates was clearly observed in the minimum spanning tree (Fig. 6).

P. ultimum displayed polymorphism in $25 \%$ of the SSR and $5 \%$ of the AFLP loci evaluated, with three to seven alleles per SSR locus. In the SSR analysis, this species presented the smallest mean expected heterozygosity $(\mathrm{He}=0.59)$, polymorphism information content (PIC $=0.53)$, number of private alleles, and Shannon's information index $(I=1.08)$ (Table 2, Fig. 2); but the highest observed heterozygosity $(H o=0.66)$. AMOVA revealed no genetic differentiation $\left(\operatorname{SSR} \Phi_{\mathrm{PT}}=0.003 ; \operatorname{AFLP} \Phi_{\mathrm{PT}}<0.001\right)$ among nursery populations. Gene flow analysis $(\mathrm{Nm}=30.24)$ suggested genetic exchange among lineages may occur (Table 2). UPGMA and PCoA of SSR (not shown) and AFLP data revealed two discrete isolate groups not associated with nursery of origin (Figs. 3 and 4; Supplementary Figs. 3B and 4). Nine of the isolates had unique AFLP genotypes, while 21 isolates belonged to two clonal lineages, the first included two isolates from nursery B and the second included 19 isolates from both nurseries. STRUCTURE analysis produced an optimum $K$ value of 2 (Fig. 5). The two populations identified were not associated with nursery of origin and were

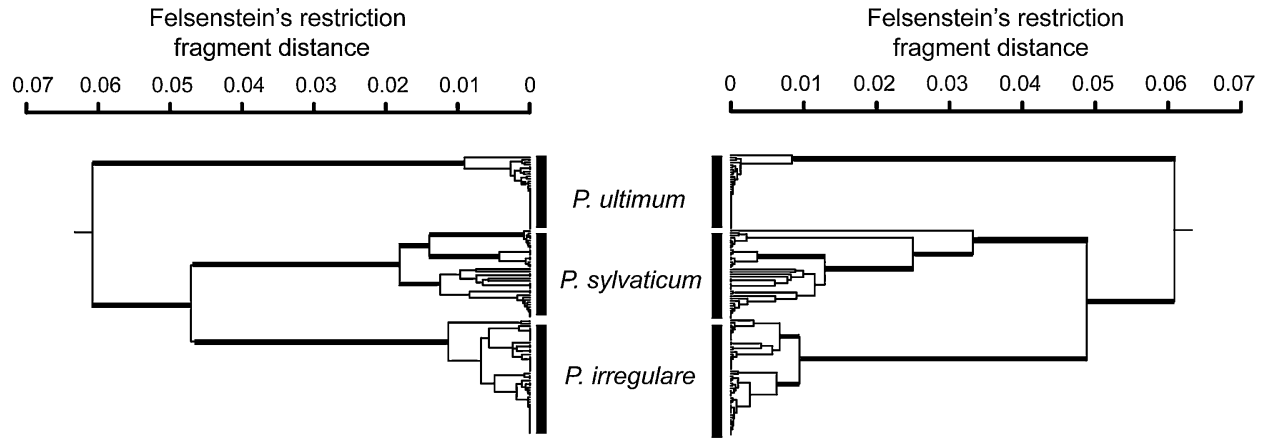

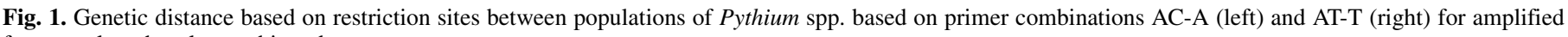
fragment length polymorphism data. 
congruent with the AFLP UPGMA and PCoA results (Figs. 3 and 4, respectively), and with the SSR minimum spanning tree (Fig. 6).

$P$. sylvaticum had the largest percentage of polymorphic loci (46\% SSR; $85 \%$ AFLP). SSR analysis revealed that this species had the highest number of SSR alleles per locus $(\mathrm{Na}=23)$, mean expected heterozygosity $(\mathrm{He}=0.81)$, polymorphism information content (PIC $=0.79$ ), and private alleles, as well as the highest Shannon's information index $(I=2.14$; Table 2, Figure 2); but it had the lowest observed heterozygosity $(H o=0.39)$. AMOVA revealed significant genetic differentiation $\left(\operatorname{SSR} \Phi_{\mathrm{PT}}=0.065 ; \mathrm{AFLP}_{\mathrm{PT}}=\right.$ $0.220)$ among nursery populations. Gene flow analysis $(\mathrm{Nm}=4.32)$ suggested genetic exchange among lineages may occur. UPGMA and PCoA of AFLP and the SSR minimum spanning tree (Figs. 3, 4, and 6; Supplementary Figs. 3C and 4) identified four groups, three of which clustered together in the UPGMA (Fig. 3) and contained isolates from both nurseries $\mathrm{B}$ and $\mathrm{C}$. The fourth group only contained isolates from nursery C. Nineteen of the isolates had unique AFLP genotypes, while 18 isolates belonged to 8 clonal lineages with two or three isolates each. None of the clonal lineages contained isolates from more than one nursery. STRUCTURE analysis of SSR data produced an optimum $K$ value of 2 (Fig. 5), with the corresponding populations not associated with nursery of origin.

TABLE 2. Summary of genetic diversity and population differentiation statistics for all simple sequence repeat (SSR) loci

\begin{tabular}{|c|c|c|c|c|c|c|c|c|c|c|}
\hline Species & Locus & $N e^{\mathrm{a}}$ & $N a^{\mathrm{b}}$ & $I^{\mathrm{c}}$ & $H e^{\mathrm{d}}$ & $H o^{\mathrm{e}}$ & $\mathrm{PIC}^{\mathrm{f}}$ & $N m^{\mathrm{g}}$ & $F_{S T}^{\mathrm{h}}$ & Allele frequencies \\
\hline \multirow[t]{5}{*}{ P. irregulare } & 63108TGGTGT4-9 & 4.94 & 6.00 & 1.66 & 0.80 & 0.49 & 0.77 & 1.90 & 0.12 & 0.24 \\
\hline & 63108TG1-3 & 2.71 & 5.00 & 1.16 & 0.63 & 0.19 & 0.57 & 1.79 & 0.12 & 0.51 \\
\hline & 63108ACA1-67 & 2.18 & 3.00 & 0.89 & 0.54 & 0.60 & 0.46 & 7.91 & 0.03 & 0.59 \\
\hline & 63108TTC4-15 & 2.59 & 3.00 & 1.02 & 0.61 & 0.83 & 0.54 & 13.93 & 0.02 & 0.50 \\
\hline & Mean & 3.10 & 4.25 & 1.18 & 0.65 & 0.53 & 0.59 & 6.38 & 0.07 & 0.46 \\
\hline \multirow[t]{6}{*}{ P. ultimum } & PU009 & 2.17 & 5.00 & 1.01 & 0.55 & 0.40 & 0.49 & 35.57 & 0.01 & 0.62 \\
\hline & PU012 & 2.24 & 3.00 & 0.95 & 0.56 & 0.67 & 0.50 & 53.17 & 0.00 & 0.60 \\
\hline & PU013 & 2.74 & 7.00 & 1.26 & 0.64 & 0.97 & 0.58 & 44.50 & 0.01 & 0.47 \\
\hline & PU014 & 2.34 & 4.00 & 1.09 & 0.59 & 0.60 & 0.54 & 6.44 & 0.04 & 0.57 \\
\hline & PU008 & 2.47 & 5.00 & 1.08 & 0.59 & 0.67 & 0.53 & 11.50 & 0.02 & 0.55 \\
\hline & Mean & 2.39 & 4.80 & 1.08 & 0.59 & 0.66 & 0.53 & 30.24 & 0.02 & 0.56 \\
\hline \multirow[t]{7}{*}{ P. sylvaticum } & 63108CAA2-41 & 11.09 & 22.00 & 2.69 & 0.91 & 0.49 & 0.90 & 2.99 & 0.08 & 0.16 \\
\hline & 63108TG1-3 & 6.32 & 13.00 & 2.15 & 0.83 & 0.44 & 0.82 & 4.86 & 0.05 & 0.28 \\
\hline & 63108CAA3-11 & 6.98 & 13.00 & 2.20 & 0.85 & 0.46 & 0.83 & 2.88 & 0.08 & 0.24 \\
\hline & P50CA1-68 & 4.24 & 8.00 & 1.68 & 0.76 & 0.51 & 0.73 & 3.30 & 0.07 & 0.38 \\
\hline & 63108CTC-81 & 13.16 & 23.00 & 2.83 & 0.93 & 0.16 & 0.92 & 7.33 & 0.03 & 0.15 \\
\hline & P50TC1-2 & 2.27 & 8.00 & 1.26 & 0.55 & 0.30 & 0.53 & 4.55 & 0.05 & 0.65 \\
\hline & Mean & 7.34 & 14.50 & 2.14 & 0.81 & 0.39 & 0.79 & 4.32 & 0.06 & 0.31 \\
\hline
\end{tabular}

${ }^{a} \mathrm{Ne}=$ effective number of alleles.

b $N a=$ observed number of alleles.

c $I=$ Shannon's Information index.

${ }^{\mathrm{d}} \mathrm{He}=$ gene diversity/expected heterozygosity.

e $\mathrm{Ho}=$ observed heterozygosity.

f PIC = polymorphism information content (6); describes the usefulness of a genetic marker based on its level of polymorphism and the distribution of the frequencies of its alleles within a population (46). PIC $>0.5=$ highly informative; $0.25<$ PIC $>0.5=$ reasonably informative; PIC $<0.25=$ slightly informative. g $N m=$ absolute number of migrants per generation, estimates gene flow from $F_{S T} ; N m=0.25\left(1-F_{S T}\right) / F_{S T}$.

${ }^{\text {h }} F_{S T}=$ fixation index is a measure of population differentiation, based on the probability of inbreeding among populations $(66)$. $F_{S T}<0.05=$ low genetic differentiation; 0.05 to $0.15=$ moderate; 0.15 to $0.25=$ great; and, $>0.25=$ very great $)$.
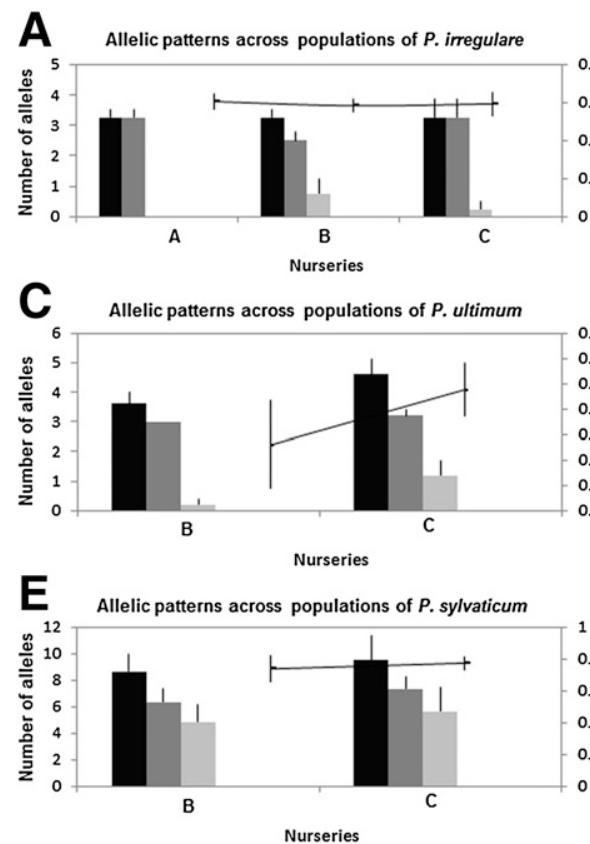

B
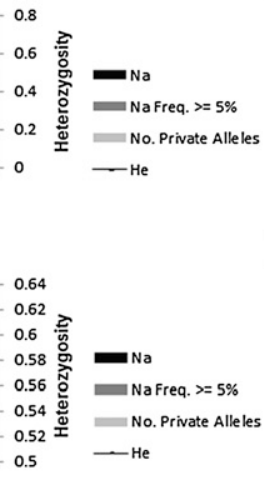

\section{D}

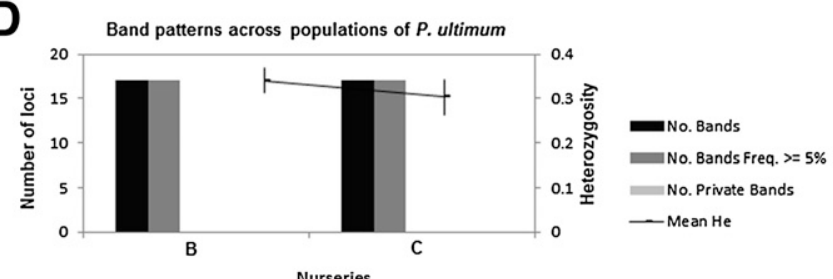

F
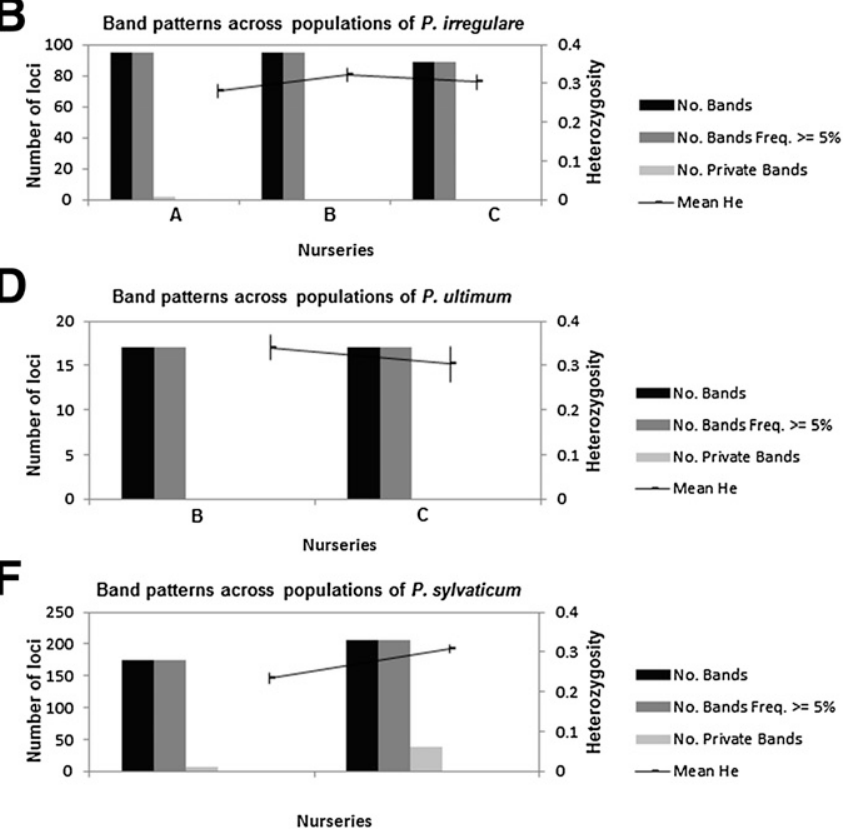

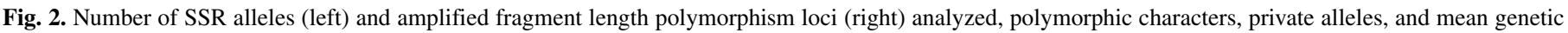

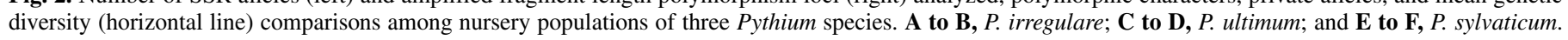


All isolates from nursery B and most from nursery C $(n=11)$ were assigned to the same population; four isolates from nursery $\mathrm{C}$ were assigned to the second population whereas five isolates from nursery $\mathrm{C}$ were identified as putative hybrids between the two populations.

Analysis of the index of association showed significant linkage among loci $(P<0.005)$ for all populations with and without clone censoring, suggesting a predominantly clonal reproductive mode or selfing for all three Pythium species (Table 3, Fig. 6).

Comparison of AFLP and SSR markers. Overall, the phylogenetic trees obtained by both SSR and AFLP markers were congruent, even though terminal topology varied. The Mantel matrix correspondence test showed highly significant correlations between SSR and AFLP similarity matrices in P. ultimum $(\mathrm{Rxy}=0.405 ; P=$ $0.003)$ and $P$. irregulare (Rxy $=0.310 ; P=0.001)$; whereas, only a very small correlation was found in $P$. sylvaticum $(\mathrm{Rxy}=0.12 ; P=$ $0.024)$. Tree topological distances between methods are shown in Table 4 with markers producing trees significantly more structured than random with the exception of P. ultimum, but this could be due to the low number of unique isolates. These results indicate that there is a concordance between major clades within the trees, but the individual level signal differs.

\section{DISCUSSION}

The population structure and genetic diversity of $P$. irregulare, $P$. ultimum, and $P$. sylvaticum from three nurseries in the states of Oregon and Washington were analyzed using microsatellite and AFLP markers. Population structure analyses revealed significant geographic structure among nursery populations of $P$. irregulare and $P$. sylvaticum (low to moderate, respectively), while no significant structure was observed in P. ultimum. The three species also displayed an intrinsic population structure not associated with geographic distribution. Such structure suggested the prevalence of certain lineages within each species in the studied areas, two lineages in $P$. irregulare and $P$. ultimum and four in $P$. sylvaticum. Estimates of genetic diversity indicated that $P$. sylvaticum was the most diverse of the three species, with lower levels of diversity observed in P. irregulare, followed closely by P. ultimum. P. sylvaticum, P. irregulare, and P. ultimum had 36 (97\%), 26 (54\%), and $18(60 \%)$ unique SRR genotypes. Nineteen P. ultimum isolates from nurseries B and $C$ shared a clonal genotype based on AFLP (Fig. 3, UG1) and SSR markers (data not shown). Group UG1 may have been introduced to both nurseries recently, because the populations have not accumulated genetic variation yet. $P$. irregulare included three clusters within two main groups, IG1 and IG2, and the distribution of isolates among groups suggest potential movement between nurseries, mostly from nursery $\mathrm{A}$ and $\mathrm{B}$ to nursery $\mathrm{C}$, and as evidenced by hybridization among IG1 and IG2 lineages in nursery C. Gene flow estimates indicated frequent migration or genetic exchange among nursery populations of the three species. Genetic exchange could occur if
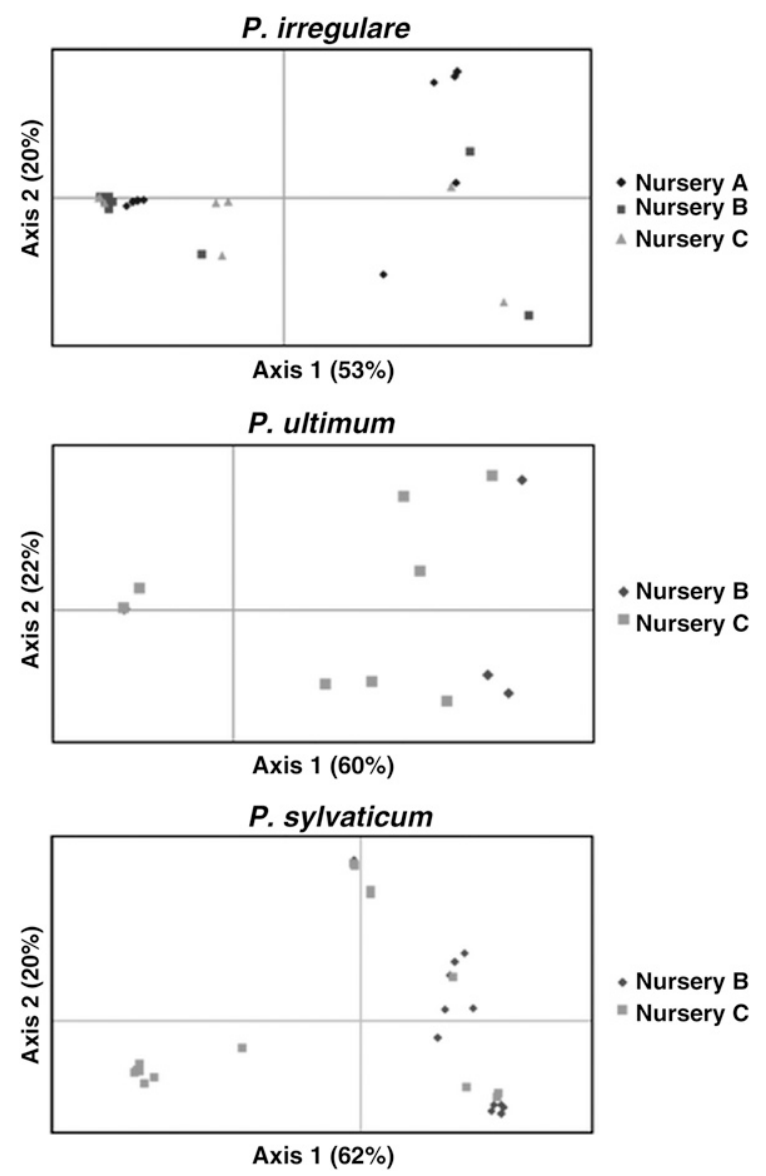

Fig. 4. Scatter plots of the first and second principal coordinates analysis of three Pythium spp. at nurseries A, B, and C based on amplified fragment length polymorphism data. P. irregulare (top); P. ultimum (middle); and P. sylvaticum (bottom).
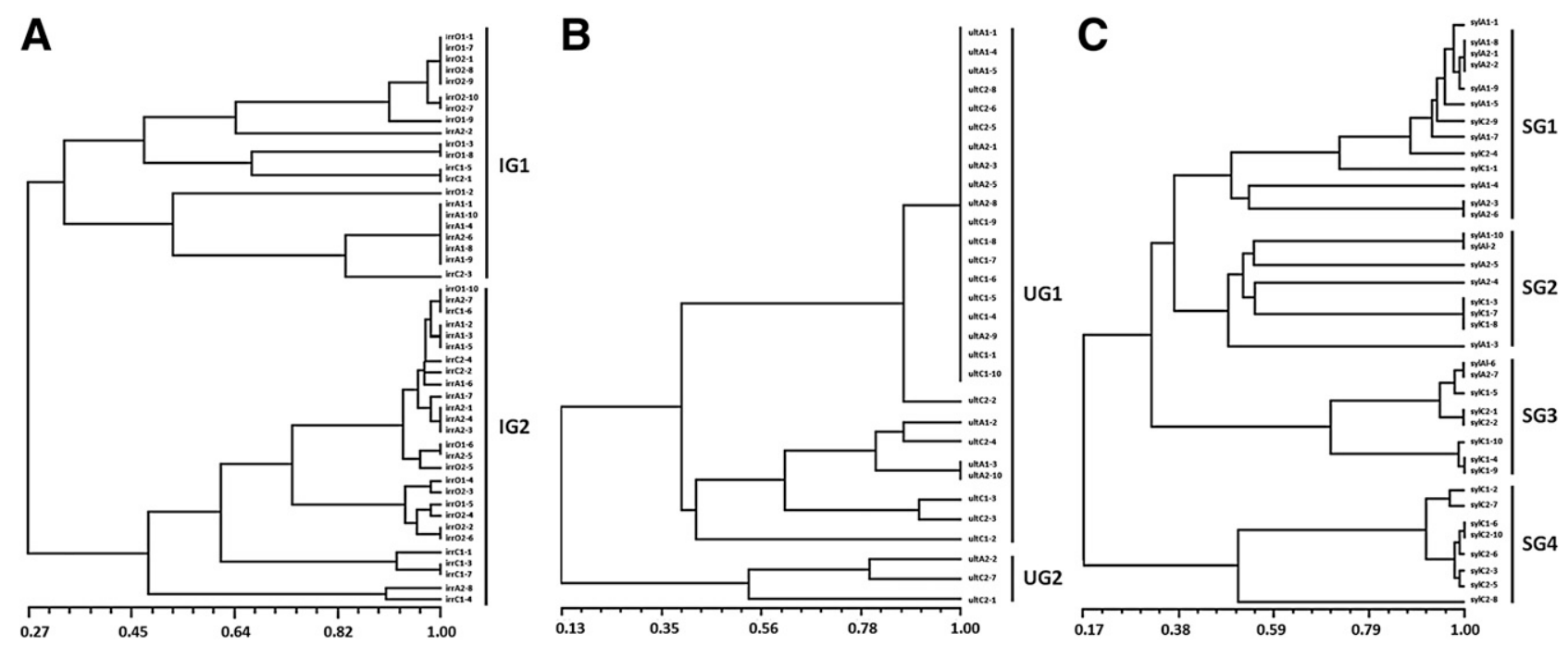

Fig. 3. UPGMA trees of three Pythium species, based on Jaccard's genetic distance obtained with amplified fragment length polymorphism markers. A, $P$. irregulare; $\mathbf{B}$, P. ultimum; and $\mathbf{C}$, P. sylvaticum. 
isolates are inadvertently moved (passive migration) among nurseries on seedlings, field equipment, or by workers, and then subsequently interbreed with existing isolates at each location.

Currently, there is little information regarding the genetic population structure of Pythium species as determined from naturally occurring Pythium populations. Many studies that used molecular markers to assess Pythium genetic diversity have been based on culture collections containing only a few isolates of each species and, in many cases, the isolates originated from multiple locations and plant hosts, not from distinct populations $(3,9,18,43,45)$. Analyses have been further complicated by the presence of cryptic species. For example, although Harvey et al. $(29,30)$ used restriction fragment length polymorphic markers to examine the genetic diversity in seven populations of $P$. irregulare from cereal crops in southern Australia, it is unknown whether the populations assessed consisted solely of $P$. irregulare s.s. isolates or if they also included the cryptic species $P$. cryptoirregulare, which was later discovered within the $P$. irregulare complex (see below). Nevertheless, there are several studies that have assessed larger numbers of Pythium isolates from distinct populations associated with agricultural production. In Oman, the structure of $P$. spinosum populations from greenhouse-grown cucumber was studied by AFLP fingerprinting analysis (3). Based on the limited genetic diversity observed and on fungicide sensitivity phenotype similarity, it was concluded that $P$. spinosum was recently introduced to Oman from a common or even unique source. Other studies of Pythium population structure come from AFLP $(4,34)$ and SSR (34) analyses of $P$. aphanidermatum isolates from the ornamental greenhouse industry in Pennsylvania (34) and a cucumber production greenhouse in Oman (4). In Pennsylvania, 123 P. aphanidermatum isolates were studied by AFLP and SSR fingerprinting analyses, which included 103 and 4 polymorphic loci, respectively. The combined analysis of AFLP and SSR data identified significant genetic diversity among isolates and population structure defined by location and mefenoxam sensitivity, but not by host (34). In Oman, $P$. aphanidermatum populations collected from a single cucumber production greenhouse in 2006 and 2011 were examined by AFLP fingerprinting analysis, aggressiveness, and mefenoxam sensitivity (4). Population structure analysis, based on 985 polymorphic AFLP loci, revealed moderate genetic structure among populations from the 2 years. While no differences in aggressiveness were observed between the 2 years, 2011 isolates were significantly more sensitive to mefenoxam than in 2006. The authors suggested that newer, more sensitive isolates were introduced into the greenhouse in the intervening years, which led to the difference in sensitivity observed between 2006 and 2011. Although limited, there is increasing information available regarding the population structure of Pythium species and previous studies have provided critical, foundational information illustrating the presence of intraspecific variation in Pythium species $(3,4,9,18,21-23,34,45)$, evidence for heterozygosis and potential outcrossing in homothallic Pythium species (18,29), interpopulational gene flow $(29,30)$, and for significant population structure due to location, host and/or mefenoxam sensitivity $(4,29,30,34)$.

The genetic structure of $P$. irregulare was first studied by Barr et al. (5), who reported two discrete groups defined by isozyme
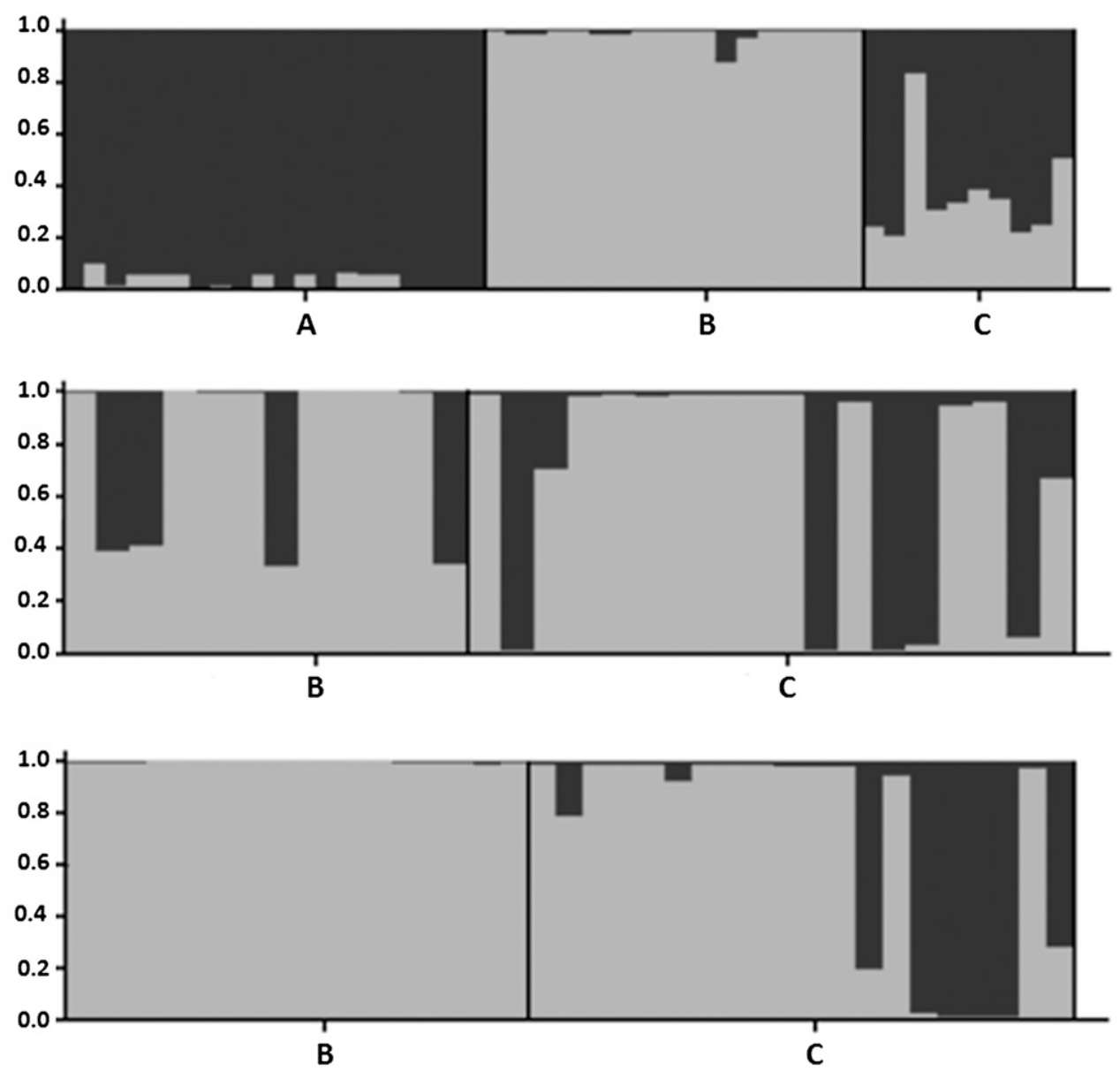

\section{Nurseries}

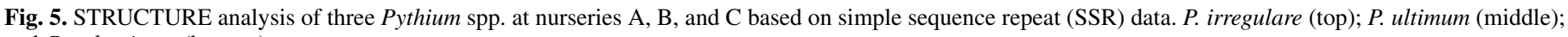
and P. sylvaticum (bottom). 
analysis. Matsumoto et al. (45) confirmed the division of $P$. irregulare into two main groups, one of which was more closely related to $P$. sylvaticum, by phylogenetic analysis of the ITS region, which provided the first genetic evidence of the paraphyly of this species. Each of the groups described by Matsumoto et al. (45) was further divided into two subgroups with strong bootstrap support, suggesting the possibility of multiple cryptic species within P. irregulare s.l. Garzon et al. $(22,23)$ later characterized the population structure of $P$. irregulare s.l. using DNA sequence analysis of genomic (ITS) and mitochondrial loci (coxI-II), and AFLP fingerprinting, subsequently reporting two distinct clades within $P$. irregulare (22) that corresponded to Matsumoto's groups I and II. The first clade was later described as a new species, $P$. cryptoirregulare, and the second was defined as $P$. irregulare s.s. based on similarities to the $P$. irregulare neotype culture CBSnr 733.94; GenBank AY598702 (23,37). Pythium irregulare s.s. overall displayed less genetic variability than $P$. cryptoirregulare and exhibited rare mefenoxam resistance. Nevertheless, there was evidence for three internal groups within $P$. irregulare s.s. The present study examined P. irregulare s.s. isolates exclusively and found evidence for two internal groups, but it is unknown how these correspond to the three internal groups reported by Garzon et al. (22) because different AFLP primer combinations were used. Although significant population structure was observed, it was small, and the number of migrants per generation confirmed that the populations identified based on genetic similarity were conspecific.

In comparison with $P$. irregulare, there is even less information regarding the genetic diversity of $P$. ultimum and no information for $P$. sylvaticum. Chen et al. (9) examined the genetic diversity and phylogenetics of 10 Pythium species, including P. ultimum, using isozyme analyses of 13 enzymes. Isolates of $P$. ultimum formed a monophyletic group, with several isolates from different locations and hosts displaying identical banding patterns. Garzon et al. (21) also examined the genetic diversity of $12 P$. ultimum isolates, as part of a larger study, and found considerable genetic diversity among them (37\% mean genetic distance); of these, 11 formed a monophyletic clade supported by AFLP and ITS sequence data, while one isolate represented a distinct operational taxonomic unit. A recent study by Eggertson et al. (14) reported four putative species within $P$. ultimum based on multilocus phylogenetic analysis, including DNA sequences of four hyper-variable gene regions of the P. ultimum genome. According to that study, isolates previously identified as $P$. ultimum var. ultimum (including all $P$. ultimum isolates used in the present study) will be classified as $P$. ultimum s.s. based on the neotype isolate and those previously identified as $P$. ultimum var. sporangiiferum will be classified as $P$. sporangiiferum. Names for the other two species have yet to be determined and the characterization and description of these four species are underway (A. Levesque, personal communication). Although our results identified two groups within the $P$. ultimum populations analyzed, population genetics statistics support them as intraspecific populations with low genetic differentiation. Our results found considerably less genetic diversity within the species than either Chen et al. (9) or Garzon et al. (22).
However, their studies included isolates of $P$. ultimum that were obtained from a much broader host and geographic range (nationally and internationally) than isolates used in the present study.

Although most isolates studied were heterozygous at one or more loci, results from the standardized index of association indicated that the isolates of $P$. irregulare, $P$. sylvaticum, and $P$. ultimum assessed in this study were not outcrossing. Both $P$. irregulare and $P$. ultimum are homothallic (58), and if sexual reproduction for these two species primarily occurred via self-fertilization in forestry nursery soils, we would expect the relatively narrow range of genetic variability that was observed in this study. Although outcrossing is possible for homothallic species such as P. irregulare and P. ultimum $(19,29)$, we did not find statistically supported evidence for this in the current study. P. sylvaticum, on the other hand, is mostly heterothallic (58) and has the potential to reproduce sexually mainly by outcrossing, but it is also capable of occasional selfing $(48,53)$. Because of its heterothallic nature, we would expect greater variability among isolates of this species compared with $P$. irregulare and P. ultimum, which was the case in this study. However, the standardized index of association for both $P$. sylvaticum populations was relatively high, which indicated that no statistically significant evidence of outcrossing was found. Reproduction in these $P$. sylvaticum populations may therefore be mostly asexual via hyphal swellings and through propagation of mycelium on infected plant materials (58). However, this and the lack of statistical support for outcrossing does not explain why we observed hybrid genotypes (admixed or hybrid between two populations of the same species) in the three Pythium species of this study. In order to produce these hybrid genotypes, outcrossing between isolates from different nurseries must have occurred. We suggest that our initial sampling design, which was intended to assess the broad diversity of Pythium species in the soil across 1.3 ha field plots, may not have had the statistical power to detect outcrossing at a much smaller spatial scale where individual isolates would be more likely to interact and hybridize. Therefore, additional studies of Pythium populations are needed with a more appropriate sampling design to clarify whether outcrossing is present among Pythium species in forest nurseries.

Results from this study provide direct evidence that Pythium species and isolates have been moved among forest nurseries of the Pacific Northwest. The limited genetic diversity and the presence of numerous clonal $P$. ultimum isolates suggest that this species may have been relatively recently introduced into nurseries $B$ and $C$. Alternatively, the homothallic nature of this pathogen may significantly limit the genetic diversity of this species if reproduction primarily occurs asexually or via inbreeding. In contrast, the broad distribution of $P$. irregulare and $P$. sylvaticum lineages, and the presence of genotypes potentially produced by rare admixture events in these species, indicate that the predominant lineages may have been present in the sampled locations for longer time, with possible recent introductions of new lineages. The most likely route for pathogen movement, given current nursery practices, is on the roots of infected seedlings brought in from other locations or on shared field equipment. Although both practices have occurred for decades (J. Weiland,

TABLE 3. Index of association analysis for simple sequence repeat markers in Pythium species ${ }^{\mathrm{a}}$

\begin{tabular}{|c|c|c|c|c|c|c|c|c|c|c|}
\hline \multirow[b]{2}{*}{ Index nursery } & \multicolumn{4}{|c|}{ P. irregulare } & \multicolumn{3}{|c|}{ P. ultimum } & \multicolumn{3}{|c|}{ P. sylvaticum } \\
\hline & A & B & $\mathrm{C}$ & Pooled & B & $\mathrm{C}$ & Pooled & $\mathrm{B}$ & $\mathrm{C}$ & Pooled \\
\hline$N$ & 20 & 18 & 10 & 48 & 12 & 18 & 30 & 17 & 20 & 37 \\
\hline $\bar{r}_{d}^{\mathrm{b}}$ & 0.534 & 0.493 & 0.247 & 0.407 & 0.651 & 0.428 & 0.456 & 0.220 & 0.194 & 0.148 \\
\hline$P$ value & $<0.001$ & $<0.001$ & 0.004 & $<0.001$ & $<0.001$ & $<0.001$ & $<0.001$ & $<0.001$ & $<0.001$ & $<0.001$ \\
\hline$N^{\mathrm{c}}$ & 8 & 9 & 10 & 27 & 8 & 12 & 20 & 17 & 19 & 36 \\
\hline $\bar{r}_{d}^{\mathrm{c}}$ & 0.307 & 0.254 & 0.247 & 0.246 & 0.534 & 0.240 & 0.287 & 0.220 & 0.157 & 0.140 \\
\hline$P$ value & 0.004 & 0.004 & 0.002 & $<0.001$ & $<0.001$ & $<0.001$ & $<0.001$ & $<0.001$ & $<0.001$ & $<0.001$ \\
\hline
\end{tabular}

a $P$ values based on 2,000 permutations. Clone censoring was performed by representing each multilocus genotype once per population. $N=$ sample size.

b $\bar{r}_{d}=$ standardized index of association.

c Clone-censored data. 
unpublished data) and there is evidence that several Pythium lineages are shared among the three nurseries (this study), each nursery also retains a distinct Pythium community (60). Consequently, data indicates there is a significant risk of unintentionally introducing new Pythium species or isolate genotypes on incoming nursery stock. For example, $P$. ultimum was only found twice and $P$. sylvaticum was never found at nursery A in Washington during the original survey in 2008. Therefore, this nursery would be at particular risk for an accidental introduction of $P$. sylvaticum and $P$. ultimum on nursery stock from nurseries B or C, where both of these Pythium species were more abundant. In addition, our results indicate that populations of $P$. irregulare at nursery $\mathrm{C}$ are hybrids of those from nurseries $\mathrm{A}$ and $\mathrm{B}$, suggesting that this species may have been brought into nursery $\mathrm{C}$ from these two other locations. There is also a significant risk for accidentally introducing fungicide-resistant isolates. In a previous study, two mefenoxam resistant isolates of $P$. ultimum, ult A2-2 from nursery $\mathrm{B}$ and ult $\mathrm{C} 2-7$ from nursery $\mathrm{C}$, were identified and found to be 5,000 to $6,000 \times$ more mefenoxam resistant than all other isolates of $P$. ultimum (64). Both of these isolates were shown to be genetically related by AFLP and SSR analyses in this study (Fig. 3), and it seems likely that they were transported from one nursery to the other on infected nursery stock.

The practical implications of this study for the forest nursery industry are many-fold. First, nursery managers should consider management practices that will reduce the risks associated with bringing in new nursery stock whenever possible. One way of achieving this might be to designate specific fields for the production of seedlings purchased from other nurseries and reserve the remaining field space for in-house production. This would help keep pathogen populations associated with the incoming nursery stock separate from those already present and serve to contain any new pathogen genotypes to a more limited region of the nursery. Second, fungicidal drenches should be investigated for their potential to suppress Pythium populations on incoming stock. Even though oomycete-specific fungicides are often fungistatic and not fungicidal against $P$ ythium species at recommended label doses (64), they might be able to suppress and prevent establishment of new Pythium genotypes if they are used to treat incoming nursery stock before they are planted into field production sites. Finally, fast and reliable diagnostic tests, such as DNA macroarrays or loopmediated isothermal amplification (56), are needed to help growers assess the amount of Pythium colonization and the identity of Pythium species present on incoming transplants. A previous study showed that the amount of Pythium on the roots of transplants can

TABLE 4. Topological distance between neighbor-joining trees ${ }^{\mathrm{a}}$

\begin{tabular}{lccc}
\hline Comparison & P. irregulare & P. sylvaticum & P. ultimum \\
\hline AC-A: SSR & 74 & 58 & 54 \\
AT-T: SSR & 74 & 54 & 54 \\
AC-A: AT-T & 62 & 36 & 46 \\
Random & $(86-90)$ & $(64-68)$ & $(50-54)$ \\
\hline
\end{tabular}

a This distance can represent the number of changes one tree will need to undergo in order to become the next tree. SSR, simple sequence repeat; AC-A, amplified fragment length polymorphic (AFLP) marker with AC-A primer; AT-T, AFLP with AT-T primer; and random, 95\% confidence interval for 1,000 random pairs of trees.
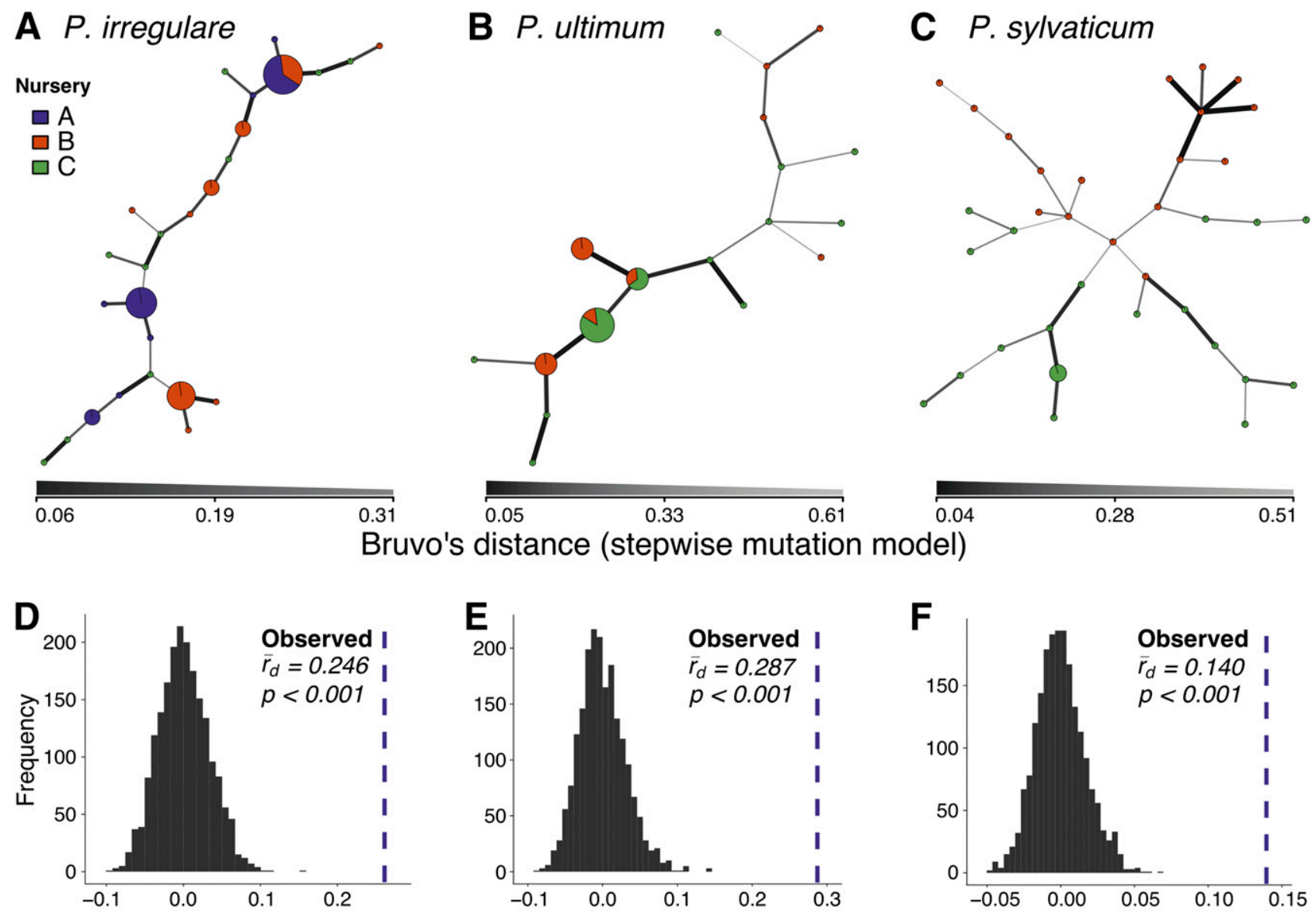

\section{Standardized index of association $\left(\bar{r}_{d}\right)$}

Fig. 6. A to C, Minimum spanning networks of multilocus genotypes by species. Each circle represents a unique multilocus genotype where the size of the circle is relative to the number of individuals represented in the data. Circle colors represent population membership of each multilocus genotype. Line shade and width is proportional to Bruvo's distance (shown in scale bar). D to $\mathbf{F}$, The null distribution of $\bar{r}_{d}$ (histogram) compared with the observed value (blue line) on clonecensored data from each species rejecting the null hypothesis of random mating. 
vary from 0 to $45 \%$, depending on the source nursery (62). Knowing this type of information beforehand can help growers assess the risk of bringing in nursery stock from other locations. If molecular markers for fungicide resistance can be identified among forest nursery Pythium species, these might also prove useful for screening nursery stock.

The present study assessed the genetic diversity present in forest nursery populations of $P$. irregulare, $P$. ultimum, and $P$. sylvaticum and provides evidence for the movement of each species among forest nurseries of the Pacific Northwest. This information can be used to monitor for shifts in pathogen populations when new Pythium genotypes are introduced on incoming nursery stock or in response to changes in nursery management practices. Future studies are needed to assess the fate of Pythium isolates on nursery stock when they are moved from one nursery to another as there are risks of accidentally introducing more aggressive genotypes or fungicide-resistant isolates into locations where they did not exist previously. These risks may currently be moderated by the frequent use of preplant methyl bromide fumigation in the industry; pathogen populations that are accidentally introduced into a particular field may be significantly reduced by the next cycle of soil fumigation. However, as this study indicates, at least some Pythium genotypes have already been effectively moved and are now established in the soil at more than one nursery. As the use of methyl bromide in forest nurseries continues to decline due to the Montreal Protocol (63), the risks associated with nursery stock movement among nurseries may increase. Additional research will be needed to determine the effectiveness of new fumigant chemistries and rates in helping to limit the spread of Pythium species and isolates in the forest nursery industry.

\section{ACKNOWLEDGMENTS}

We thank M. Larsen, J. Tabima, and F. Flores for their excellent technical support; and $\mathrm{H}$. Melouk for reviewing earlier versions of the manuscript. The use of trade, firm, or corporation names in this publication is for the information and convenience of the reader. Such use does not constitute an official endorsement or approval by the U.S. Department of Agriculture (USDA) or the Agricultural Research Service (ARS) of any product or service to the exclusion of others that may be suitable. Financial support was provided by the USDA-ARS CRIS 5358-22000-034-00D and 5358-22000039-00D.

\section{LITERATURE CITED}

1. Agapow, P. M., and Burt, A. 2001. Indices of multilocus linkage disequilibrium. Mol. Ecol. Notes 1:101-102.

2. Al-Sa'di, A. M., Drenth, A., Deadman, M. L., and Aitken, E. A. B. 2008. Genetic diversity, aggressiveness and metalaxyl sensitivity of Pythium aphanidermatum populations infecting cucumber in Oman. Plant Pathol. 57:45-56.

3. Al-Sa'di, A. M., Drenth, A., Deadman, M. L., Cock, A. W. A. M. d., Al-Said, F. A., and Aitken, E. A. B. 2008. Genetic diversity, aggressiveness and metalaxyl sensitivity of Pythium spinosum infecting cucumber in Oman. J. Phytopathol. 156:29-35.

4. Al-Sadi, A. M., Al-Ghaithi, A. G., Al-Balushi, Z. M., and Al-Jabri, A. H. 2012. Analysis of diversity in Pythium aphanidermatum populations from a single greenhouse reveals phenotypic and genotypic changes over 2006 to 2011. Plant Dis. 96:852-858.

5. Barr, D. J. S., Warwick, S. I., and Desaulniers, N. L. 1997. Isozyme variation, morphology, and growth response to temperature in Pythium irregulare. Can. J. Bot. 75:2073-2081.

6. Botstein, D., White, R. L., Skolnick, M., and Davis, R. W. 1980. Construction of a genetic linkage map in man using restriction fragment length polymorphisms. Am. J. Hum. Genet. 32:314-331.

7. Brown, A. H. D., Feldman, M. W., and Nevo, E. 1980. Multilocus structure of natural populations of Hordeum spontaneum. Genetics 96: 523-536.

8. Bruvo, R., Michiels, N. K., D'Souza, T. G., and Schulenburg, H. 2004. A simple method for the calculation of microsatellite genotype distance irrespective of ploidy level. Mol. Ecol. 13:2101-2106.

9. Chen, W., Schneider, R. W., and Hoy, J. W. 1992. Taxonomic and phylogenetic analyses of ten Pythium species using isozyme polymorphisms. Phytopathology 82:1234-1244.
10. Cooke, D. 2014. Fingerprinting Techniques. Fungal Plant Pathogens. C. R. Lane, P. A. Beales, and K. J. D. Hughes, eds. CABI, Cambridge, MA.

11. Csárdi, G., and Nepusz, T. 2006. The igraph software package for complex network research. InterJournal, Complex Systems 1695.

12. Dumroese, R. K., and James, R. L. 2005. Root diseases in bareroot and container nurseries of the Pacific Northwest: Epidemiology, management, and effects on outplanting performance. New For. 30:185-202.

13. Earl, D. A., and vonHoldt, B. M. 2011. STRUCTURE HARVESTER: A website and program for visualizing STRUCTURE output and implementing the Evanno method. Conserv. Genet. Resour. 4:359-361.

14. Eggertson, Q. A., Lévesque, C. A., Buell, C. R., and Hamilton, J. P. 2012. Resolving the Pythium ultimum species complex. (Abstr.) Phytopathology 102(suppl.):S4.34.

15. Escudero, M., Vargas, P., Arens, P., Ouborg, N. J., and Luceño, M. 2010. The east-west-north colonization history of the Mediterranean and Europe by the coastal plant Carex extensa (Cyperaceae). Mol. Ecol. 19:352-370.

16. Excoffier, L., Smouse, P. E., and Quattro, J. M. 1992. Analysis of molecular variance inferred from metric distances among DNA haplotypes: Application to human mitochondrial DNA restriction data. Genetics 131: 479-491.

17. Felsenstein, J. 2004. Inferring Phylogenies. 2 ed. Sinauer Associates, Sunderland, MA.

18. Francis, D. M., Gehlen, M. F., and St. Clair, D. A. 1994. Genetic variation in homothallic and hyphal swelling isolates of Pythium ultimum var. ultimum and P. ultimum var. sporangiferum. Mol. Plant-Microbe Interact. 7:766-775.

19. Francis, D. M., and St. Clair, D. A. 1993. Outcrossing in the homothallic oomycete, Pythium ultimum, detected with molecular markers. Curr. Genet. 24:100-106.

20. Gao, H., Williamson, S., and Bustamante, C. D. 2007. A Markov chain Monte Carlo approach for joint inference of population structure and inbreeding rates from multilocus genotype data. Genetics 176:1635-1651.

21. Garzon, C. D., Geiser, D. M., and Moorman, G. W. 2005. Diagnosis and population analysis of Pythium species using AFLP fingerprinting. Plant Dis. 89:81-89.

22. Garzon, C. D., Geiser, D. M., and Moorman, G. W. 2005. Amplified fragment length polymorphism analysis and internal transcribed spacer and coxII sequences reveal a species boundary within Pythium irregulare. Phytopathology 95:1489-1498.

23. Garzon, C. D., Yanez, J. M., and Moorman, G. W. 2007. Pythium cryptoirregulare, a new species within the $P$. irregulare complex. Mycologia 99:291-301.

24. Gower, J. C. 1967. Multivariate analysis and multidimensional geometry. Statistician 17:13-28.

25. Grünwald, N. J., and Hoheisel, G. A. 2006. Hierarchical analysis of diversity, selfing, and genetic differentiation in populations of the oomycete Aphanomyces euteiches. Phytopathology 96:1134-1141.

26. Grünwald, N. J., Werres, S., Goss, E. M., Taylor, C. R., and Fieland, V. J. 2012. Phytophthora obscura sp. nov., a new species of the novel Phytophthora subclade 8d. Plant Pathol. 61:610-622.

27. Hansen, E. M., Hamm, P. B., Julis, A. J., and Roth, L. F. 1979. Isolation, incidence and management of Phytophthora in forest tree nurseries in the Pacific Northwest. Plant Dis. Rep. 63:607-611.

28. Hansen, E. M., Myrold, D. D., and Hamm, P. B. 1990. Effects of soil fumigation and cover crops on potential pathogens, microbial activity, nitrogen availability, and seedling quality in conifer nurseries. Phytopathology 80:698-704.

29. Harvey, P. R., Butterworth, P. J., Hawke, B. G., and Pankhurst, C. E. 2000. Genetic variation among populations of Pythium irregulare in southern Australia. Plant Pathol. 49:619-627.

30. Harvey, P. R., Butterworth, P. J., Hawke, B. G., and Pankhurst, C. E. 2001. Genetic and pathogenic variation among cereal, medic and sub-clover isolates of Pythium irregulare. Mycol. Res. 105:85-93.

31. Hubisz, M. J., Falush, D., Stephens, M., and Pritchard, J. K. 2009. Inferring weak population structure with the assistance of sample group information. Mol. Ecol. Resour. 9:1322-1332.

32. Kamvar, Z. N., Tabima, J. F., and Grünwald, N. J. 2014. Poppr: An R package for genetic analysis of populations with clonal, partially clonal, and/or sexual reproduction. PeerJ 2:e281.

33. Kannwischer, M. E., and Mitchell, D. J. 1978. The influence of a fungicide on the epidemiology of black shank of tobacco. Phytopathology 68: $1760-1765$.

34. Lee, S., Garzón, C. D., and Moorman, G. W. 2010. Genetic structure and distribution of Pythium aphanidermatum populations in Pennsylvania greenhouses based on analysis of AFLP and SSR markers. Mycologia 102:774-784.

35. Lee, S., and Moorman, G. W. 2008. Identification and characterization of simple sequence repeat markers for Pythium aphanidermatum, P. cryptoirregulare, and $P$. irregulare and the potential use in Pythium population genetics. Curr. Genet. 53:81-93. 
36. Lévesque, C. A., Brouwer, H., Cano, L., Hamilton, J., Holt, C., Huitema, E., Raffaele, S., Robideau, G., Thines, M., Win, J., Zerillo, M., Beakes, G., Boore, J., Busam, D., Dumas, B., Ferriera, S., Fuerstenberg, S., Gachon, C., Gaulin, E., Govers, F., Grenville-Briggs, L., Horner, N., Hostetler, J., Jiang, R., Johnson, J., Krajaejun, T., Lin, H., Meijer, H., Moore, B., Morris, P., Phuntmart, V., Puju, D., Shetty, J., Stajich, J. E., Tripathy, S., Wawra, S., van West, P., Whitty, B. R., Coutinho, P. M., Henrissat, B., Martin, F., Thomas, P. D., Tyler, B. M., De Vries, R. P., Kamoun, S., Yandell, M., Tisserat, N., and Buell, C. R. 2010. Genome sequence of the necrotrophic plant pathogen Pythium ultimum reveals original pathogenicity mechanisms and effector repertoire. Genome Biol. 11:R73.

37. Lévesque, C. A., and de Cock, A. W. A. M. 2004. Molecular phylogeny and taxonomy of the genus Pythium. Mycol. Res. 108:1363-1383.

38. Li, L., Chokchai, W., Huang, X., Huang, T., Li, Q., Peng, Y., and Huang, G. 2011. Comparison of AFLP and SSR for genetic diversity analysis of Brassica napus hybrids. J. Agric. Sci. 3:101-110.

39. Li, Y., Cooke, D. E. L., Jacobsen, E., and Lee, T. D. 2013. Efficient multiplex simple sequence repeat genotyping of the oomycete plant pathogen Phytophthora infestans. J. Microbiol. Methods 92:316-322.

40. Linderman, R., Dixon, W., Fraedrich, S., and Smith, R. S., Jr. 1994. Alternatives to methyl bromide: Assessment of research needs and priorities for forestry, nursery, and ornamental crops. Tree Planters Notes 45:43-47.

41. Linderman, R. G., and Zeitoun, F. 1977. Phytophthora cinnamomi causing root rot and wilt of nursery-grown native western azalea and salal. Plant Dis. Rep. 61:1045-1048.

42. Liu, K., and Muse, S. V. 2005. PowerMarker: An integrated analysis environment for genetic marker analysis. Bioinformatics 21:2128-2129.

43. Martin, F. N., and Kistler, H. C. 1990. Species-specific banding patterns of restriction endonuclease-digested mitochondrial DNA from the genus Pythium. Exp. Mycol. 14:32-46.

44. Martins, W. S., Soares Lucas, D. C., de Souza Neves, K. F., and Bertioli, D. J. 2009. WebSat-A web software for microsatellite marker development. Bioinformation 3:282-283.

45. Matsumoto, C., Kageyama, K., Suga, H., and Hyakumachi, M. 2000. Intraspecific DNA polymorphisms of Pythium irregulare. Mycol. Res. 104:1333-1341.

46. Nagy, S., Poczai, P., Cernák, I., Gorji, A. M., Hegedüs, G., and Taller, J. 2012. PICcalc: An online program to calculate polymorphic information content for molecular genetic studies. Biochem. Genet. 50:670-672.

47. Nei, M., and Li, W. H. 1979. Mathematical-model for studying geneticvariation in terms of restriction endonucleases. Proc. Natl. Acad. Sci. USA 76:5269-5273.

48. Papa, K. E., Campbell, W. A., and Hendrix, F. F., Jr. 1967. Sexuality in Pythium sylvaticum: Heterothallism. Mycologia 59:589-595.

49. Paradis, E., Claude, J., and Strimmer, K. 2004. APE: Analyses of phylogenetics and evolution in R language. Bioinformatics 20:289-290.

50. Peakall, R., and Smouse, P. E. 2006. GENALEX 6: Genetic analysis in Excel. Population genetic software for teaching and research. Mol. Ecol. Notes 6:288-295.

51. Penny, D., and Hendy, M. D. 1985. The use of tree comparison metrics. Syst. Zool. 34:75-82.

52. Perneel, M., Tambong, J. T., Adiobo, A., Floren, C., Saborío, F., Lévesque, A., and Höfte, M. 2006. Intraspecific variability of Pythium myriotylum isolated from cocoyam and other host crops. Mycol. Res. 110: 583-593.

53. Pratt, R. G., and Green, R. J. 1973. The sexuality and population structure of Pythium sylvaticum. Can. J. Bot. 51:429-436.

54. Pritchard, J. K., Stephens, M., and Donnelly, P. 2000. Inference of population structure using multilocus genotype data. Genetics 155:945-959.

55. R Core team. 2014. R: A Language and Environment for Statistical Computing. R Foundation for Statistical Computing, Vienna, Austria.

56. Schroeder, K. L., Martin, F. N., de Cock, A. W. A. M., Levesque, C. A., Spies, C. F. J., Okubara, P. A., and Paulitz, T. C. 2013. Molecular detection and quantification of Pythium species: Evolving taxonomy, new tools, and challenges. Plant Dis. 97:4-20.

57. Sutherland, J., and Dennis, J. 1992. Pythium water mould in British Columbia forest nurseries. Seed Seedling Ext. Topics 5:9-10.

58. van der Plaats-Niterink, A. J. 1981. Monograph of the genus Pythium. Stud. Mycol. 21:1-242.

59. Vos, P., Hogers, R., Bleeker, M., Reijans, M., van de Lee, T., Hornes, M., Frijters, A., Pot, J., Peleman, J., Kuiper, M., and Zabeau, M. 1995. AFLP: A new technique for DNA fingerprinting. Nucleic Acids Res. 23: 4407-4414.

60. Weiland, J. E. 2011. Influence of isolation method on recovery of Pythium species from forest nursery soils in Oregon and Washington. Plant Dis. 95: 547-553.

61. Weiland, J. E., Beck, B. R., and Davis, A. 2013. Pathogenicity and virulence of Pythium species obtained from forest nursery soils on Douglasfir seedlings. Plant Dis. 97:744-748.

62. Weiland, J. E., Leon, A. L., Edmonds, R. L., Littke, W. R., Browning, J. E., Davis, A., Beck, B. R., Miller, T. W., Cherry, M. L., and Rose, R. 2011. The effects of methyl bromide alternatives on soil and seedling pathogen populations, weeds, and seedling morphology in Oregon and Washington forest nurseries. Can. J. For. Res. 41:1885-1896.

63. Weiland, J. E., Littke, W. R., and Haase, D. L. 2013. Forest nurseries face critical choices with the loss of methyl bromide fumigation. Calif. Agric. 67:153-161.

64. Weiland, J. E., Santamaria, L., and Grünwald, N. J. 2014. Sensitivity of Pythium irregulare, P. sylvaticum, and P. ultimum from forest nurseries to mefenoxam and fosetyl-Al, and control of Pythium damping-off. Plant Dis. 98:937-942.

65. Weir, B. S., and Ott, J. 1997. Genetic data analysis II. Trends Genet. 13:379.

66. Wright, S. 1969. Evolution and the Genetics of Populations, Vol. 2: The Theory of Gene Frequencies. University of Chicago, Chicago, IL.

67. Yeh, F. C. R.-C. Y., Boyle, T., Ye, Z.-H., and Mao, J. X. 1997. POPGENE: The user-friendly shareware for population genetic analysis. Molecular Biology and Biotechnology Centre, University of Alberta, Canada.

68. Yin-Ling, Zhou, W., Motohashi, K., Suga, H., Fukui, H., and Kageyama, K. 2009. Development of microsatellite markers for Pythium helicoides. FEMS Microbiol. Lett. 293:85-91.

69. Zietkiewicz, E., Rafalski, A., and Labuda, D. 1994. Genome fingerprinting by simple sequence repeat (SSR)-anchored polymerase chain reaction amplification. Genome 20:176-183.

70. Zuker, M. 2003. Mfold web server for nucleic acid folding and hybridization prediction. Nucleic Acids Res. 31:3406-3415. 